NOTAS

\title{
EL BRUJO DE LA MÚSICA BLANCA
}

Mauricio López Noriega*

$\mathrm{P}$ un momento dado levanta la vista de las páginas impresas para cerrar los ojos y hacer consciente y pleno el placer de la lectura, la fruición que despierta en el espíritu una historia no sólo bien contada, sino quién sabe por qué relevante; para todo escritor que sabe percibir el oficio, sus mecanismos y herramientas, las estrategias escondidas en la construcción del texto, el aliento que aletea bajo las aguas; para quien de pronto siente el taedium vitae apoderándose de las horas, y cae en la cuenta de que quizá nunca haya de vivir salvo situaciones comunes y corrientes, cotidianas,

\footnotetext{
* Departamento Académico de Estudios Generales, ITAM.
}

sin grandes tragedias, sin alegrías muy hondas, imaginando el posible respaldo de frases como "escribir a alguien es la única forma de esperarlo sin hacerse daño"; para quienes la fantasía o la sorpresa resultan conceptos vacíos, palabras inconcretas, sin peso; para los que llegan a la noche con el propósito insuperable de dormir, sin miramientos; para los cómplices, porque serán consolados, Baricco escribe.

Recursos al parecer sumamente sencillos, como el rompimiento de la sintaxis mediante una puntuación distinta ("compraba y vendía gusanos de seda" / "Compraba y vendía. Gusanos de seda") o los cambios mínimos en la repetición de una secuencia (los nombres del lago, en Seda, o la 
enumeración progresiva en Océano Mar); personajes bien elegidos pero no imposibles, además de tramas de historias que seguramente nos habría gustado atestiguar; todo ello convierte a Alessandro Baricco en un creador de ritmos. Pienso que, sin saberlo, lo que cautiva en sus novelas son los ritmos, y su armonía interna, ecos que resuenan por dentro una vez detenida la lectura; no lo percibimos -mérito del buen escritor-, quizá no la primera vez, pero el proceso de seducción se origina desde el ritmo regente de cada narración, de manera que cuando terminamos el libro no sabríamos describir por qué nos genera esa gran sensación de levedad, definitivamente menos gris que la de Kundera. Y no nos ahorra nada, salvo el gusto houellebecquiano por mostrarnos un mundo peor del que ya conocemos, las corrosivas atmósferas del posmodernismo europeo y de la disciplina del desaliento; tampoco revela un mundo contrario, ideal, y por lo tanto improbable.

En sus historias, podemos encontrar de súbito el más profundo desconsuelo, hondo terror y feroz, como "El vientre del mar", en Océano Mar: "Y para siempre nosotros, los que hemos conocido las cosas verdaderas, para siempre nosotros, los retornados del vientre del mar, para siempre nosotros, los expertos y los sapientes, para siempre seremos inconsolables"; han visto la cara informe de Ananke, la Necesidad, relato de un náufrago que miró aquello que la gran mayoría del ser urbano no enfrentará, ni en sus peores sueños (nuestra creatividad es de otro signo, menos naturaleza). Imposible no recordar aquella sombría pintura, $L a$ balsa de Medusa. Ritmo. Contrapuntos: un pintor de marinas que, para ser coherente, utiliza como material sólo agua de mar; una muchacha, hija única, enferma de sensibilidad, cuya cura se hace presente en medio de una tormenta: dosis terapéutica de apremiante faloterapia. $\mathrm{O}$ el hombre que escribe carta tras carta a una prometida futura, para entregárselas todas cuando por fin la encuentre. Un cura estrafalario, un profesor maniático que mide límites inverosímiles en la naturaleza, una mujer bellísima y una posada atendida por ¿ángeles? Todos reunidos por un vínculo: el mar.

O una historia de boxeo con un estribillo poco infantil ("-iQue te den por culo, Larry!, -Por culo...”) narrada por un niño genio, experto en física y matemáticas, que se relata a sí mismo en voz alta encerrado en el baño, por emergencia, por hacerse compañía, para vivir desde otro lado algo que divierta el peso de su enajenante brillantez; o un western inteligente, cuyo tiroteo final es una explosión de sorpresa 
calculada, agua y oro; y ráfagas de humor, de saludable humor abierto y confiado en lo increíblemente difícil que puede ser comprar dos hamburguesas con queso y dos jugos de naranja: la serie de complicaciones evidentes que surgen cuando en un sitio de comida rápida, Shatzy, la muchacha, no precisamente común, que escribe el western, obtiene por fin lo que pidió, por fin solamente lo que pidió, pero se encuentra ya de tal manera exhausta que tira la maldita hamburguesa tras ganar un premio y un globo. O la única forma posible de mirar las Nymphéas de Monet, sólo comprensibles desde los ojos de una oriental con 'capacidades diferentes'; o, todo al mismo tiempo, el Ensayo sobre la honestidad intelectual, esbozado por un profesor universitario que es incapaz de dejar de llorar. City.

$\mathrm{O}$ asistir, en Tierras de cristal, a una revelación fatal que se va desvistiendo como los pétalos de una flor venenosa: Jun conoce por vez primera a Mormy, el hijo bastardo del señor Rail, su señor Rail; dos pensamientos cuando mira al niño y piensa en la madre de ese niño: "Esa puta era una negra". Pero añade después: "Esa puta era bellísima"; y luego la sentencia que domina buena parte del libro y que anticipa una venganza absolutamente femenina: "Hola Mormy. Me llamo Jun y no soy tu madre. Y nunca lo seré [...] Fue con dulzura — nos aclara el narrador-, no obstante, hay que imaginárselo dicho con dulzura." De fondo, la confianza en un mundo que despertaba al progreso, lleno de promesas, ciudad de cristal, y su reverso: la obsesión de un hombre por crear una vía férrea para él, para su gozo y alegría, una locomotora que no tenga destino, salvo el deslizarse velozmente ante el aterrado espanto de los demás.

Quizá menos decimonónico que el aire de sus primeras novelas, $\mathrm{Sin}$ sangre es un punto de fuga (que de alguna manera anticipa la recreación que hizo después con la Ilíada de Homero), al permitir la posibilidad de pensar que inclusive los hechos de sangre más irracionales e inhumanos pueden llegar a resolverse lejos del dolor y de la espiral de violencia que termina siempre en más derramamientos inútiles. ¿Esquilo?

Novecento: escuchar a un pianista que vive en un barco, sin descender jamás -Baricco es también crítico musical, El alma de Hegel y las vacas de Wisconsin-, hacer música fuera de este mundo, mientras el violento balanceo en medio del océano, mar, provoca que tanto piano como banquillo con pianista bailen de un lado al otro del salón; la música no deja de sonar. Ni un solo instante. De Novecento se hizo una película. 
Su última novela, Esta historia, es la persecución de un sueño, un poco como el ferrocarril del señor Rail, una carretera que no es una carretera, que acaba donde empieza, lo suficientemente larga para que quepa en ella la vida entera, en cada curva, en cada oscilación, en cada recta, un lugar para lanzar el coche para que viaje por todo lo que se ha visto y que no se ha olvidado, sueño insensato materializado en una pista de carreras interminable, perfecta. Una forma de poner orden en el caos del mundo posterior a la Primera guerra mundial; un gesto último de Ultimo Parri, mediante el cual puede realizar aquello para lo que nació, porque pocos son los que, de vez en vez, consiguen cumplir su destino. Una invitación. Si nos importa, claro.

O la música blanca de Seda.

Probablemente sea la mejor manera de empezar con las novelas de Alessandro Baricco; el título, Seda, es ya una descripción de la historia. "Que nadie se espere aviones, lavadoras, psicoanalistas", mezclilla; el tema no es necesariamente una historia de amor (o tal vez porque precisamente lo es, y entonces duele), el ritmo, casi minimalista, japonés, consigue envolvernos en una telaraña suavísima, llena de admiraciones y gestos extraños y maravillosos, como una nube de pájaros exóticos o un niño que es un mensaje, incomprendido; frases que se quedan grabadas sin daño en la memoria del fuego: "Es un dolor extraño [...] Morir de nostalgia por algo que no vivirás nunca." Y la carta. La carta de una mujer: poesía erótica sin melindres ni aspavientos; delicada, resuelta, recuerda un poco zonas de Pierre Louÿs. Hace años ya, al presentar Seda, Baricco: “Todas las historias tienen una música propia. Ésta tiene una música blanca. Es importante decirlo porque la música blanca es una música extraña, a veces te desconcierta: se ejecuta suavemente y se baila lentamente. Cuando la ejecutan bien es como oír el silencio y a los que la bailan estupendamente se les mira y parecen inmóviles. La música blanca es algo rematadamente difícil."

La literatura de Baricco: ¿se puede viajar el viaje de otro? La experiencia cursa con sonrisas íntimas, guiños secretos, intransferibles, esa rara certeza de levedad, de vuelo en ciernes que nos produce, lentamente, página a página. No es difícil recordar que una vez, al menos una vez, por la razón y bajo la circunstancia que se quiera. Leer también es un riesgo.

La lógica limpia nunca está divorciada del sentido del humor; la expresión lúdica, cuando es inteligente, es también lúcida. Como Erasmo, 
por decir. ¿Habrá perdido la novela actual la limpieza de pensamiento que otorgan las matemáticas, el sentido del hombre que juega? Es Sciascia, desde otro lado: suavidad para explicar la crudeza de lo inexorable, sin privarla de los rasgos humanos, incluyendo sentimientos fuera de moda (¿por ejemplo, no resulta casi obsceno tener que pedir ternura?), fuera de la estética de la abyección. Un ejemplo mínimo, un fragmento de la Oración por alguien que se ha perdido, y en consecuencia, para ser sinceros, oración por mí, del padre Pluche, en Océano mar:

Señor Buen Dios
tened paciencia
de nuevo soy yo.
Veréis, aquí las cosas
van bien,
quien más, quien menos
se las arregla,
en la práctica
se encuentra siempre la manera
la manera de apañarse,
vos me comprendéis,
en resumen el problema no es
éste.
El problema es otro,
si tenéis la paciencia de escuchar
de escucharme
de.
El problema es este camino
[...]
Así
yo cojo

esta oscuridad

y la pongo

en vuestras manos.

$\mathrm{Y}$ os pido,

Señor Buen Dios, que la tengáis con vos

sólo una hora

tenedla en vuestras manos

sólo lo que sea necesario

para disolver lo negro

para disolver el mal

que provoca en la cabeza

esa oscuridad

y en el corazón

ese negro

¿queréis?

$[\ldots]$

total

de encontrarla ya me encargo yo

de ver

dónde está.

Una nimiedad

para vos,

tan grande

para mí.

¿Me escucháis

Señor Buen Dios?

No es pediros demasiado

pediros que.

No es ofensa

esperar que vos.

No es idiota

ilusionarse con.

Y además es sólo una oración, que es una forma de escribir el perfume de la espera.

Baricco narrador estimula la reflexión sobre lo fragmentario; sin embargo, al final se permite siempre 
una clase de visión unitaria a la cual es difícil dejar de someterse, una especie de solidaridad con el escritor. Por ejemplo, los caracteres femeninos que pinta y que tal vez pudiera ser, además del ritmo y del humor, el eje rector de sus novelas: la recuperación de la verdadera femineidad. No faltará quien se alarme frente a esta afirmación; para mí, sin idealizarla, sin sobajarla, Baricco devuelve a la mujer su paraíso perdido.

Por eso, la frescura. Me referí, como ejemplo, a Michel Houellebecq, podría nombrar a Ellis o Beigbeder, varios otros; para quien termina una novela suya como Plataforma o Ampliación del campo de batalla, el resultado conserva una propuesta, pero es lo contrario: ya nada tiene sentido porque se ha perdido el sentido de buscar sentido (aunque debo decir que con Lanzarote me reí a carcajadas; al principio). En Baricco, fantasía y realidad, una serie de técnicas narrativas extraordinariamente depuradas, honestidad, ilusión. La palabra, el ritmo en la palabra, no pierde el poder de embrujar. La imagen nos circunda; pero cuando aparece el mago se hace el silencio, y en el silencio se escucha. ¿Lo escuchado es tan verdaderamente aterrador?

“Allá en el fondo está la muerte, pero no tenga miedo. Sujete el reloj con una mano, tome con dos dedos la llave de la cuerda, remóntela suavemente. Ahora se abre otro plazo, los árboles despliegan sus hojas, las barcas corren regatas, el tiempo como un abanico se va llenando de sí mismo...", Cortázar, en sus Instrucciones para dar cuerda al reloj. Leer es una forma digna de abrir plazos, siempre, aunque se sepa por anticipado que allá en el fondo está la muerte. Nos queda, sin duda, elegir nuestras lecturas.

Refugio, amparo. ¿Gracia? Las novelas de Baricco acercan en algo a estas ideas. Tal vez no lleguen a convertirse plenamente en esperanza, pero quizá participan un paso previo, un pro-yecto: algo lanzado hacia delante. 